\title{
CORRESPONDENCE.
}

\section{ANALYSIS OF REPLIES TO THE QUESTIONNAIRE ON THE TEACHING OF GEOMETRY.}

To the Editor of the Mathematical Gazelte.

330 Banbury Road, Oxford.

DEAR EDITOR, - I have had 190 replies to my two queries; among the replies being some welcome ones from overseas. I am very grateful to all my correspondents.

To take [II] first, that the angular points of congruent or similar triangles should be quoted in corresponding order, there was of course no dissentient voice though many ridiculed the expression "supreme importance" With regard to the placing of one set below the other, most welcomed it for similar triangles but were doubtful in cases of congruence. There was also doubt about " insisting" This I am sorry for, as it is an essential part of good style to be careful of "order". Examiners must condone many slovenly faults, but teachers need not.

However, the chief interest attaches to [I], that the fundamental theorem on areas is "Parallelograms on the same base and between the same parallels are equal in area".

151 are in favour : some most emphatically;

14. are indifferent, or have no decided views;

6 think it does violence to freedom of thought;

18 prefer the mensuration method of dealing with such equalities;

1 says he would like to scrap this theorem altogether.

\section{0}

May I in further advocacy of this theorem, as standing in a class by itself, explain that accepting it does not tie a teacher to start with it, or to make no use of the mensuration methods when they are obviously advantageous. They can be deduced immediately afterwards. But this theorem asserts equality of areas, and proves it, as a matter of pure geometry, quite irrespective of how areas must be measured. It is as absurd to say that this theorem holds because each parallelogram equals a certain rectangle as it would be to say that two lumps of gold which balance are equal because the same number of sovereigns could be coined from each : they are equal because they balance, quite irrespective of other particulars. Well, my parallelograms are my lumps of gold! And there I leave the matter. I can prove they balance, without bringing in a sordid rectangle.

25 May, 1932.

Alfred Lodge.

\section{A CHALLENGE.}

To the Editor of the Mathematical Gazette.

Sir,--In the days of old when mathematicians understood one another, and tempered the wind to the shorn lamb, and their science was a Whetstone of Witte, it was customary for people such as Fermat and Pascal and even Leibniz or a Bernoulli to fling challenges to their friends in playful or serious mood ; and progress in knowledge has notoriously resulted.

Perhaps the abeyance of this custom has not been an unmixed good. A fair test of this would be the performance of a modern scientist, trained to research, on an old-fashioned Cambridge problem paper, such as was set, for instance, by Stokes or Kelvin or Clerk Maxwell in days gone past. 